\title{
Standards, Regulation and Conformity Assessment for $\mathrm{mCHP}$
}

\begin{abstract}
Combined Heat and Power (mCHP) relies on standards in around a dozen technical areas, related to topics like product safety, electricity grid access, and environmental performance. This chapter provides an overview over relevant standards and their effect on mCHP. Under the European 'New Approach', many of these standards define 'essential requirements' in line with European regulation. This link makes standards important elements for conformity assessment and proving $\mathrm{mCHP}$ appliances' regulatory compliance. Standards are therefore key enablers for mCHP's developers to place the technology on the European market. The chapter concludes with an overview over the effects of standards and regulation on innovation in the $\mathrm{mCHP}$ case.
\end{abstract}

Keywords Standards - European regulation - European new approach Effects of standards on innovation - Conformity assessment Regulatory compliance

Standards, together with regulation and conformity assessment, have been crucial for the development of mCHP. While our study was initially focussing on the role and management of standards for the innovation, it soon transpired from our interviews that they are inextricably linked to European and national regulation and conformity assessment of $\mathrm{mCHP}$ appliances. In Sect. 3.1, we outline which standards have been relevant for the technology's development. Section 3.2 explores the link between

(C) The Author(s) 2019

P. M. Wiegmann, Managing Innovation and Standards, https://doi.org/10.1007/978-3-030-01532-9_3 
standards and regulation and its effects on mCHP. Following this, we discuss the need for conformity assessment and the role that standards and regulation play in this context (Sect. 3.3). Finally, we shed light on additional effects that standards had on the development of $\mathrm{mCHP}$ in Sect. 3.4.

\subsection{Relevant STANDARDS FOR MCHP}

Standards posed requirements for key aspects of mCHP technology, such as product safety, energy efficiency, and connections to the electricity grid, which needed to be fulfilled in order to provide the intended value for buyers and gain approval for market entry. A list of all relevant standards, that were mentioned during the interviews, can be found in Table 3.1. Many of these standards are interrelated.

The standards identified in Table 3.1 broadly fulfilled two main functions for mCHP's development process: The first function is defining the interfaces to link mCHP to complementary technologies, such as the national electricity grid and electrical and gas installations in buildings. These infrastructures were essential to enable the innovation to deliver the new aspects of its value proposition-generating electricity that can be used by a device's owner and/or fed into the electricity grid.

The second main function of standards for the innovation is related to support proving the compliance of $\mathrm{mCHP}$ appliances and their components with regulatory requirements (e.g. gas and electrical safety, energy efficiency and requirements for connecting devices to the electricity grid). This function has been key for the development of mCHP, based on the link between standards and regulation in the case, which we outline in detail in Sects. 3.2 and 3.3.

All interviewees stressed the particular importance of the product standard (EN 50465- "Gas appliances-Combined heat and power appliance of nominal heat input inferior or equal to $70 \mathrm{~kW}$ ") for the development of $\mathrm{mCHP}$. This product standard addresses key elements of the technology, such as safety and energy efficiency, and defines minimum performance requirements for these dimensions of $\mathrm{mCHP}$ appliances. It has been key in outlining how mCHP appliances can meet regulatory requirements (see Sect. 3.2) and in supporting the conformity assessment of the appliances (see Sect. 3.3). When the technology's development started, this standard did not exist yet in its current form and did not cover all technological approaches to mCHP: 
Table 3.1 Relevant standards for $\mathrm{mCHP}$

\begin{tabular}{|c|c|c|}
\hline Level of the standard & Technical aspects covered & Standard(s) \\
\hline \multirow[t]{4}{*}{$\begin{array}{l}\text { Links between mCHP appli- } \\
\text { ance and other systems }\end{array}$} & $\begin{array}{l}\text { Connection to the electricity } \\
\text { grid }\end{array}$ & $\begin{array}{l}\text { EN } 50438^{\text {a }} \text {; standards } \\
\text { developed by ENTSO-E } \\
\text { (European Network of } \\
\text { Transmission System } \\
\text { Operators for Electricity), } \\
\text { national grid codes }\end{array}$ \\
\hline & $\begin{array}{l}\text { Connection to a building's } \\
\text { internal electrical wiring }\end{array}$ & $\begin{array}{l}\text { National standards for } \\
\text { electrical installations } \\
\text { (e.g. VDE-AR-N } 4105 \text { in } \\
\text { Germany, NEN } 1010 \text { in the } \\
\text { Netherlands) }\end{array}$ \\
\hline & $\begin{array}{l}\text { Communication between } \\
\text { distributed electricity } \\
\text { producing devices (e.g. } \\
\text { other mCHP appliances, } \\
\text { solar panels) to ensure grid } \\
\text { stability }\end{array}$ & $\begin{array}{l}\text { IEC 61850-7-420, } \\
\text { VHPready consortium } \\
\text { standard }\end{array}$ \\
\hline & $\begin{array}{l}\text { Quality and composition of } \\
\text { natural gas used to operate } \\
\text { mCHP appliances }\end{array}$ & EN 16726 \\
\hline \multirow[t]{5}{*}{ mCHP appliance as a whole } & $\begin{array}{l}\text { Product standards: cover } \\
\text { product safety; energy } \\
\text { efficiency; minimum perfor- } \\
\text { mance requirements }\end{array}$ & $\begin{array}{l}\text { EN } 50465 \text { (used for } \\
\text { certification of appliances } \\
\text { against European regulatory } \\
\text { requirements), IEC } 62282 \text { - } \\
3-400 \text {, at early stages of the } \\
\text { development also DVGW } \\
\text { VP } 109 \text { and VP } 119\end{array}$ \\
\hline & Product safety & IEC 62282-3-100 \\
\hline & Electrical safety & EN 60335 \\
\hline & $\begin{array}{l}\text { Quality management stand- } \\
\text { ards needed to make the } \\
\text { appliance eligible for finan- } \\
\text { cial support offered by some } \\
\text { national governments }\end{array}$ & $\begin{array}{l}\text { Microgeneration } \\
\text { Certification Standard } \\
(\text { MCS 2011) }\end{array}$ \\
\hline & $\begin{array}{l}\text { Standards describing test } \\
\text { methods to be used when } \\
\text { assessing the product's } \\
\text { conformity to regulatory } \\
\text { requirements }\end{array}$ & EN 437 and others \\
\hline
\end{tabular}


Table 3.1 (continued)

\begin{tabular}{|c|c|c|}
\hline Level of the standard & Technical aspects covered & Standard(s) \\
\hline \multirow[t]{2}{*}{$\begin{array}{l}\text { Components of } \mathrm{mCHP} \\
\text { appliance }^{\mathrm{b}}\end{array}$} & $\begin{array}{l}\text { Burners and burner controls } \\
\text { Electrical safety of } \\
\text { components }\end{array}$ & $\begin{array}{l}\text { EN } 298, \text { EN } 13611 \\
\text { EN } 60730\end{array}$ \\
\hline & \multicolumn{2}{|c|}{$\begin{array}{l}\text { Product standards for various components, such as gas } \\
\text { valves, pressure controllers, shut-off valves, pressure sen- } \\
\text { sors, etc. }\end{array}$} \\
\hline
\end{tabular}

aThe abbreviation 'EN' stands for 'Europäische Norm' and refers to European standards developed by the European Standardisation Organisations (ESOs) CEN, CENELEC and/or ETSI

bThe overview over relevant standards for components is incomplete since the product standard EN 50465 refers to 65 other standards on this level, which were not all named individually in the interviews. Nevertheless, this overview gives a good impression of the range of such standards

At first you have to deal with the product standard. But at the moment that we did the development, it wasn't there. We did the development, the basic development, we started by the end of 2005 and at that moment there was no standard.

This initial absence of the key standard had important implications for the technology's development and made writing this standard a priority for the industry in managing the standards related to the innovation, as we outline in Sect. 5.2.2.

\subsection{Regulation FOR MCHP and Its Relationship WITH STANDARDS}

Relevant regulation for $\mathrm{mCHP}$ covers the areas of product safety, energy efficiency and grid connections (see Table 3.2 for a list of all regulatory texts that were mentioned as relevant during the interviews). This regulation defines 'essential requirements' which mCHP appliances must meet if they are sold on the European market. In line with the European 'New Approach', these essential requirements laid down in the regulation are formulated on a relatively abstract level and do not prescribe technical details or solutions that need to be implemented to fulfil them. Standards provide important guidance regarding how to reach these requirements, as outlined below. 
Table 3.2 Relevant regulation for $\mathrm{mCHP}$

\begin{tabular}{|c|c|c|}
\hline Type of regulation & Regulation & Relevance for $m C H P$ \\
\hline \multirow[t]{8}{*}{ European Directives } & $\begin{array}{l}\text { Energy-Related Products } \\
\text { Directive (ErP, also referred to } \\
\text { as Ecodesign Directive) }\end{array}$ & $\begin{array}{l}\text { Imposes minimum requirements } \\
\text { for energy efficiency of ener- } \\
\text { gy-using products }\end{array}$ \\
\hline & Energy Labelling Directive & $\begin{array}{l}\text { Defines a labelling scheme for } \\
\text { energy-related products }\end{array}$ \\
\hline & $\begin{array}{l}\text { Cogeneration Directive (CHP), } \\
\text { replaced in } 2012 \text { by the Energy } \\
\text { Efficiency Directive }\end{array}$ & $\begin{array}{l}\text { Defines measures to increase the } \\
\text { EU's energy efficiency targets, } \\
\text { including promoting more } \\
\text { energy efficient heating systems }\end{array}$ \\
\hline & Gas Appliances Directive (GAD) & $\begin{array}{l}\text { Imposes requirements for the } \\
\text { safety of gas-powered products }\end{array}$ \\
\hline & Low Voltage Directive (LVD) & $\begin{array}{l}\text { Imposes requirements for elec- } \\
\text { trical safety }\end{array}$ \\
\hline & $\begin{array}{l}\text { Electromagnetic Compatibility } \\
\text { Directive (EMC) }\end{array}$ & $\begin{array}{l}\text { Imposes requirements regarding } \\
\text { emitting and accepting electro- } \\
\text { magnetic interference }\end{array}$ \\
\hline & Machinery Directive (MD) & $\begin{array}{l}\text { Imposes safety requirements } \\
\text { for machines with moving parts } \\
\text { (mainly relevant for Stirling- } \\
\text { based mCHP appliances) }\end{array}$ \\
\hline & $\begin{array}{l}\text { European Network Code on } \\
\text { Requirements for Generators } \\
\text { (NC RfG), }\end{array}$ & $\begin{array}{l}\text { Imposes requirements for con- } \\
\text { necting to the electricity grid }\end{array}$ \\
\hline National regulation & National electricity laws & $\begin{array}{l}\text { Define (financial) conditions } \\
\text { under which electricity can be } \\
\text { fed into electricity grids }\end{array}$ \\
\hline
\end{tabular}

\subsubsection{Harmonised Standards Providing 'Presumption of Conformity'}

Under the European 'New Approach', the high-level requirements formulated in directives are supported by harmonised standards. These standards provide detailed specifications of the essential requirements, such as test methods to be used in assessing whether a product meets the essential requirements. Such harmonised standards are developed by the ESOs following requests by the European Commission. The European Commission then carries out an assessment whether the contents of these standards satisfy the essential requirements. If a standard passes this assessment, it is listed in the Official Journal of the European Union along with the directive against which it is harmonised. 
Once a standard has been harmonised in this procedure, complying with the standard gives a product 'presumption of conformity' with the associated European Directives. This means that any product which implements a harmonised standard is assumed to meet the essential requirements imposed by the directive:

Someone who develops such a product (...) can work with the standards and can then assume that he also fulfils the requirements from the directives in this way. (...) This is called 'presumption of conformity' if a standard is listed under a directive in the Official Journal (...) which helps from a technical point of view. (translated from German)

\subsubsection{Fulfilling 'Essential Requirements' Without Relying on Harmonised Standards}

Although relying on harmonised standards is a straightforward and commonly used way of proving compliance with regulatory requirements, their use remains voluntary (European Commission, 2017). Manufacturers are also permitted to demonstrate in other ways that they reach a performance level that satisfies the regulation's essential requirements.

A first way of doing so is implementing other standards developed by the European Standardisation Organisations (ESOs-CEN, CENELEC, and ETSI), even if they are not harmonised. These standards are assumed to reflect the current state of technological development, meaning that implementing them in an innovation is seen as following good practice. This also applies to the key product standard in the $\mathrm{mCHP}$ case (EN 50465). Due to conflicts between the European Commission and the European heating industry regarding the calculation methods for $\mathrm{mCHP}$ appliances' energy efficiency (see Sect. 5.2.2), this standard has not been harmonised yet at the time of writing. Nevertheless, it has emerged as the generally accepted standard detailing the essential requirements from the relevant European Directives for $\mathrm{mCHP}$ appliances.

In addition to or as an alternative to relying on standards, manufacturers may also demonstrate their product's equivalent performance to the level described in the standard without using any standard: 
If his [a manufacturer's] product has a solution that is not covered by the standard (..), this is not forbidden. (...) [But] it has to be written in the development documentation that he (...) fulfils the requirements of the directive. (...) When he, as a manufacturer, prints the CE-mark ${ }^{1}$ on the device he confirms at this time that all relevant directives are fulfilled (...) and this has been proven through the standard and (...) his own specifications. (translated from German)

Such an approach of not relying on the standard then shifts the burden of proof that the $\mathrm{mCHP}$ appliance meets the regulatory requirements to the manufacturer:

The burden of proof that this [the product fulfilling the essential requirements] is actually the case then lies with him [the manufacturer]. (...) When he uses a harmonised standard, the presumption of conformity applies. This means that if he uses the standard, he may assume that he fulfils the essential requirement. If this [fulfilling the essential requirement] is not the case, the burden of proof does then not lie with him but with the European Commission. This is all about who is liable. (translated from German)

In addition to the issues surrounding liability when deviating from the solutions defined in a standard, taking such an approach would also require substantial additional effort and slow down the NPD process:

[Standards] rather lead to speeding up a development process, because the requirements are clear. Imagine there were no standards and we only had the directives. Because directives are laws and safety-related laws always exist. (...) Then you first would have to translate: What does such a legal requirement mean for materials, for testing, for technology, for time response? So standards, because they are general specifications, are actually accelerating means for the development. (translated from German)

In practice, the interviewed manufacturers therefore based the designs of their mCHP appliances on standards wherever possible and avoided using other technical solutions which would have required them to

\footnotetext{
${ }^{1}$ By placing the CE-mark on a product, a manufacturer confirms that it meets all European regulatory requirements and has passed all relevant conformity assessment procedures.
} 
demonstrate compliance to regulatory requirements in other ways. This further underlines the importance of standards for the innovation and also had implications for the management of standards, where the industry sometimes invested substantial resources in order to influence standards, rather than implementing alternative solutions into their products (see Chapter 4).

\subsection{Assessing Conformity to Essential Requirements IN THE MCHP CASE}

Because the essential requirements in the relevant regulation are mandatory (see Sect. 3.2), mCHP appliances can only be sold in the European market once their compliance to these requirements has been proven. While a declaration by the manufacturer, confirming that the requirements are met, is sufficient for many product groups, this is not the case for $\mathrm{mCHP}$. Due to the inherent safety risks of gas-powered appliances, conformity assessment must be carried out by an accredited certification body which has been authorised by the government to carry out this assessment for the relevant European Directives. This party issues a certificate if the requirements are met $^{2}$ :

[For] a gas appliance, a manufacturer cannot simply develop an appliance, produce it, and sell it. He needs third-party certification. This means he must go to an accredited testing laboratory. The product is tested on its conformity, strictly speaking to the directive but in practice to the standard. Then, a notified body issues the certificate. Only once he has this, he can sell it in Europe. (translated from German)

Such independent test laboratories (often referred to by the legal term 'notified bodies') assess the technology and against essential requirements in the relevant directives. Notified bodies choose an appropriate basis for certification which defines both the requirements that $\mathrm{mCHP}$ appliances must fulfil and the methods, which are used to assess the fulfilment. Usually, the product standard (EN 50465 in the mCHP case) is

\footnotetext{
${ }^{2}$ In addition, manufacturers can choose to obtain batch approval for their appliances. This means that they are tested according to less strict criteria and allows manufacturers to sell a limited number of appliances before obtaining full certification.
} 
used for this purpose. It defines both requirements and test methods but (at least in theory) test laboratories may also deviate from this:

This inspector, who is employed by this institute, decides which basis he brings forward or draws upon to conduct the assessment. And in this, he is relatively free. So, if he says... He could still say today 'the 50465 is not sufficient for me'. This would not correspond to the facts, but he could always draw on another standard if this was necessary in his opinion. (translated from German)

This discretion in choosing the basis for the certification process led to different approaches among testing institutes in the early stages of mCHP's development, when EN 50465 did not yet exist in its current form and therefore no standard detailed the essential requirements for mCHP appliances. In interviews with OEMs, we were told about various related standards (e.g. for conventional condensing boilers) being used as a preliminary basis for testing by the notified bodies. Another approach, which was described in an interview with a notified body, was developing a test regime directly based on the relevant directives:

When we started this process, typically for fuel cell systems, there was no standard. So we had to certify directly on the directive. We have the essential requirements of the directive. So what we did, we created our test plan and said 'okay if you meet this, then we can certify against the Gas Appliance Directive'. So there was a lot of freedom for us, but in the end, as a competent notified body, we had to make a decision 'it's safe enough'. So, we could handle different technologies which were not addressed by standards. But it also means a very good relation between us and the manufacturer to really understand the technology and for them to understand what our safety requirements are.

\subsubsection{Standards Providing Certainty for Conformity Assessment}

The potentially different approaches to certifying mCHP appliances that could be followed in the absence of standards meant some uncertainty for the NPD process because the exact requirements for market access only became clear when the notified bodies were invoked into the companies' NPD activities. As Sect. 4.2.2 shows, the stages of development at which notified bodies were involved varied between companies, meaning that the magnitude of the resulting uncertainty also differed across 
actors in the industry. Nevertheless, having standards (in particular EN 50465 ) in place to provide more detailed information about essential requirements, as outlined in Sect. 3.2, helped all involved parties' NPD activities because this reduced leeway for different interpretations of the essential requirements:

It is very important for industry that not everybody interprets the directive differently every day and at the end the certification laboratory differently than the manufacturer. (translated from German)

In this way, standards provided important information about required performance and test procedures to prove this performance which could be used during the technology's development. Standards thus reduced the effort needed for $\mathrm{mCHP}$ appliances to pass the certification process. They reduced the need for extensive proofs of technical solutions meeting the essential requirements and provided a basis for a common understanding of these requirements:

So for them [the manufacturers], it's easier that there is now a standard pointing clearly what the relevant [requirements] are.

In fulfilling this function in the certification process, standards supported mCHP's access to the European market and therefore played an essential role in enabling the technology's diffusion. While using standards remains voluntary and other solutions are acceptable, there was a widespread sentiment among the interviewees that adhering to standards related to the applicable European Directives (see Table 3.2) was almost a necessary condition for bringing $\mathrm{mCHP}$ technology to market and that other solutions should only be chosen in exceptional cases.

\subsection{Standards' Additional EfFects on mCHP's Development and Diffusion}

Interviewees reported that the standards which were relevant for $\mathrm{mCHP}$ (see Table 3.1) had both positive and negative effects for their innovation activities. They emphasised the effects of standards on the certainty regarding regulatory requirements and certification (see Sects. 3.2 and 3.3). These aspects were a major focus of their activities related to managing standards (see Chapters 4 and 5). 
In addition, the experts also reported other effects of standards on both the development and diffusion of mCHP. The positive effects named in this context include standards often being useful information sources; standards supporting access to complementary infrastructures (e.g. the electricity grid); standards allowing the industry to signal mCHP's benefits to other actors; and standards helping build economies of scales for the innovation. Negative effects on the innovation usually were perceived when standards were out-of-date or required standards were missing. These perceived effects were the basis for how actors in the industry managed standards in the case (see Chapters 4 and 5). We explain the effects that standards had in the case in detail below.

\subsubsection{Support of Standards for mCHP's Development}

Often standards served as useful information sources in the development of $\mathrm{mCHP}$, not only about regulatory requirements and testing procedures (see Sects. 3.2 and 3.3), but also about other topics. Especially in technological areas where the companies had no previous experience, like safety mechanisms related to shortcuts and switching the device off in emergencies or measuring the amount of electricity produced, interviewees explained that they could make use of standards in their designs:

For the new functionality, especially for the generation of electricity, of course, they were new aspects for us. (...) For the things which are only new to us but which are self-evident, you have to follow them. So then standards are a good help to show you what you have to do.

In addition, because "experience that has accumulated over decades is behind standards, especially in the electro-technical and gas areas" (translated from German) this information also supported more commonplace design decisions in the innovation process:

When I do not need to ponder every time 'this material, this screw and this seal - may I or may I not?' This is definitely helpful. (translated from German)

A second way in which interviewees perceived standards to support the innovation was the role that they played in defining interfaces to link 
mCHP appliances with other elements, such as the electricity grid; electrical and gas installations in buildings; and communication between electricity producing devices (see Table 3.1). These standards have not only been providing technical information for the companies' NPD activities but also have been supporting the innovation's eventual diffusion by offering certainty for the industry and eventually customers that the appliances would work with other elements as intended and limiting customers' needed investment in changing elements like the gas installations in their houses. However, interviewees pointed out that, for important interfaces, this support was only available at later stages of mCHP's development because the needed standards did not exist at all (e.g. communication between electricity producing devices), or needed to be adapted (e.g. standards for internal wiring of buildings, see below), making these interfaces an issue to be considered in the management of standards (see Sect. 5.1).

In addition, standards also were described as supporting mCHP's diffusion by helping to signal mCHP's qualities and benefits to other actors, like consumers and governments. This particularly applies to the product standard (EN 50465) which also covers energy efficiency of the appliances and supports the requirements of the Energy Labelling Directive (see Table 3.2). EN 50465 includes a formula that allows calculating the energy efficiency of $\mathrm{mCHP}$ devices. This formula is intended to form the basis for determining an mCHP appliance's energy label, which the directive requires it to carry (although this formula was a major point of contention during the development of EN 50465-see Sect. 5.2.2).

Finally, standardisation supported the heating industry in reaching economies of scales for mCHP technology. By being able to rely on existing components from other products and standardising new key components, such as the Stirling engine, between manufacturers, the industry was able to reach higher production numbers much quicker than would otherwise have been feasible and thus bring the technology's costs down to make the price-performance ratio more competitive with other heating solutions and enable faster adoption in the market than might otherwise have been possible. 


\subsubsection{Hurdles to mCHP's Development from Standards and Related Issues}

Standards sometimes also were seen as hindering the development of mCHP. Some standards contained requirements which were based on outdated assumptions and which were difficult to implement in the innovation or would have severely limited its value to users. For example, pre-existing standards for electrical installations within buildings were written under the assumption that there are only devices in a building that consume electricity but no electricity producing devices. These standards would have required substantial changes to a building's electrical installations to install $\mathrm{mCHP}$ appliances in existing buildings, thus adding to the technology's costs and making it less attractive to consumers in the crucial market for replacement of heating boilers in existing buildings. Another example of outdated assumptions underlying standards concerned test procedures fixed in a standard which may assume a certain device-architecture and specify the assessment of certain components of an appliance which may no longer be part of a new design and have been replaced by other components.

A second notable area where standards have been imposing requirements that the interviewed companies sometimes found difficult to fulfil in $\mathrm{mCHP}$ appliances is the access to the electricity grid:

Standards can also be used to hinder technologies. The 'Network Code

Requirements for Generators' is in many areas... I don't want to say designed to... but I say it makes it very difficult, in particular for small electricity generators. (translated from German)

Another interviewee described these requirements for generators as "a real problem for small generators, because it now sweeps up any generator in Europe that is greater than 800 W in power output". One key example of a difficulty resulting from this network code is the requirement for dealing with changing network frequencies, which changed while $\mathrm{mCHP}$ was under development (see Sect. 5.2.1) due to technological developments in other realms. While it was traditionally required to switch an electricity producing appliance off in the rare cases when the grid's frequency deviates from the usual $50 \mathrm{~Hz}$, the new rules required generators to be able to remain online and adjust their own frequencies in line with 
potentially deviating grid frequencies. This development posed substantial challenges for Stirling-based $\mathrm{mCHP}$ appliances:

Now it wants you to operate things from $47 \mathrm{~Hz}$ to $52 \mathrm{~Hz}$ or something, so it's much, much broader than frequency swing, which is very difficult for a tuned Stirling engine, free-piston Stirling engine. In fact, we can't operate over that wider band.

Standards which imposed hurdles for mCHP in this manner required (sometimes extensive) action during the technology's development, either by adapting the technology or the standard, in order to avoid negative effects on mCHP's eventual chances of reaching large-scale diffusion in the market.

Although hurdles for mCHP's development sometimes arose from standards (the two examples above being the most notable ones mentioned by the interviewees), there was consensus between the interviewees that the most serious standard-related obstacles to the innovation actually resulted from the absence of needed standards (either completely or on a European level). The absence of the product standard (EN 50465 ) outlined in Sect. 3.1 was key for the development of $\mathrm{mCHP}$ and necessitated substantial efforts when the industry engaged in standardisation for the technology (see Sect. 5.2.2). In other key areas, such as the natural gas composition; exhaust emissions; access to the electricity grid; or financial compensation for energy that is fed into the electricity grid, standards only did (and to some extent still do) exist on the national but not the European level. The following quotes are three out of many in our interviews that address this issue:

So, each country has its own requirements and when you go through them, then Germany has a certain standard which involves some protections that should be in. For instance (...) how to test if you are connected to the grid. (...) So, indeed, in the United Kingdom is forbidden what is required in Germany.

And this feeding into the grid is something which I still do not completely understand. On the European level, a standard exists on this topic. This standard basically consists of a rather large number of national appendices. And it explicitly states that the respective connection requirements in the individual countries, or even regions and network operator environments 
(...) must be taken into account. And this varies tremendously across Europe. (translated from German)

And then there are the specific parts, in particular for the flue gas evacuation. There, we have a European patchwork which cannot be outdone. (translated from German)

Such differences across countries meant that different versions of $\mathrm{mCHP}$ appliances needed to be developed and certified for each country where they were intended to be sold. This implied additional development effort and made it more difficult to achieve economies of scales for the components that needed to be adapted for the local versions. However, one interviewee at the European association of the heating industry pointed out that this might not be completely against the interests of the OEMs:

Honi soit qui mal y pense. Of course, the manufacturers do not want movement of goods to be as free as the consumer might think. There are also price differences between countries and they are thereby being blocked a little bit. (translated from German)

\subsection{Overall Impact of Standards on mCHP's DEVELOPMENT}

In terms of their overall impact on the development of $\mathrm{mCHP}$, interviewees saw standards mostly positive. Although there were some negative effects, as outlined above, there was consensus among the interviewees that these were by far outweighed by the positive aspects. This sentiment is represented by the following quote which characterises standards' function as proving a foundation for the innovation's development:

The aim of standardisation is very clear. At this moment, at this early stage of the technology, it is to lay a good foundation for this technology, so that this technology can be accepted by the market. (translated from German)

Based on the characterisations of support and hurdles arising from standards, they can be grouped according to (1) their link to regulation, and 
Table 3.3 Standards' potential implications for $\mathrm{mCHP}$

\begin{tabular}{|c|c|c|c|c|}
\hline & & \multicolumn{3}{|c|}{ Standard's link to regulation } \\
\hline & & Harmonised & $\begin{array}{l}\text { Linked to regulation } \\
\text { but not harmonised }\end{array}$ & $\begin{array}{l}\text { No link to } \\
\text { regulation }\end{array}$ \\
\hline \multirow[t]{2}{*}{$\begin{array}{l}\text { Innovation's ability } \\
\text { to conform to } \\
\text { standard }\end{array}$} & Yes & $\begin{array}{l}\text { Type 1: } \\
\text { Enabling market } \\
\text { access and provid- } \\
\text { ing legal certainty }\end{array}$ & $\begin{array}{l}\text { Type } 3 \text { : } \\
\text { Facilitating market } \\
\text { access }\end{array}$ & $\begin{array}{l}\text { Type } 5 \text { : } \\
\text { Facilitating product } \\
\text { development }\end{array}$ \\
\hline & No & $\begin{array}{l}\text { Type } 2 \text { : } \\
\text { Effectively locking } \\
\text { the product out of } \\
\text { the market }\end{array}$ & $\begin{array}{l}\text { Type 4: } \\
\text { Complicating mar- } \\
\text { ket access; affect } \\
\text { product's position } \\
\text { in the market }\end{array}$ & $\begin{array}{l}\text { Type 6: } \\
\text { Requiring own } \\
\text { technological } \\
\text { solutions }\end{array}$ \\
\hline
\end{tabular}

(2) whether the innovation can conform to the standard or not. While the first characteristic determines the strength of the impact on $\mathrm{mCHP}$, the second characteristic determines whether this impact is positive or negative (see Table 3.3). Furthermore, several standards, which were needed to market mCHP appliances, did not yet exist when the technology's development started. While already existing supporting standards were relatively straightforward to manage, standards that hindered the innovation and/or were still missing required substantial attention during the technology's development. We portray these management activities in Chapters 4 and 5 .

\section{REFERENCE}

European Commission. (2017, September 25). Harmonised standards. Retrieved from http://ec.europa.eu/growth/single-market/european-standards/harmonisedstandards_en. 
Open Access This chapter is licensed under the terms of the Creative Commons Attribution 4.0 International License (http://creativecommons.org/licenses/ by $/ 4.0 /)$, which permits use, sharing, adaptation, distribution and reproduction in any medium or format, as long as you give appropriate credit to the original author(s) and the source, provide a link to the Creative Commons license and indicate if changes were made.

The images or other third party material in this chapter are included in the chapter's Creative Commons license, unless indicated otherwise in a credit line to the material. If material is not included in the chapter's Creative Commons license and your intended use is not permitted by statutory regulation or exceeds the permitted use, you will need to obtain permission directly from the copyright holder.

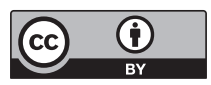

